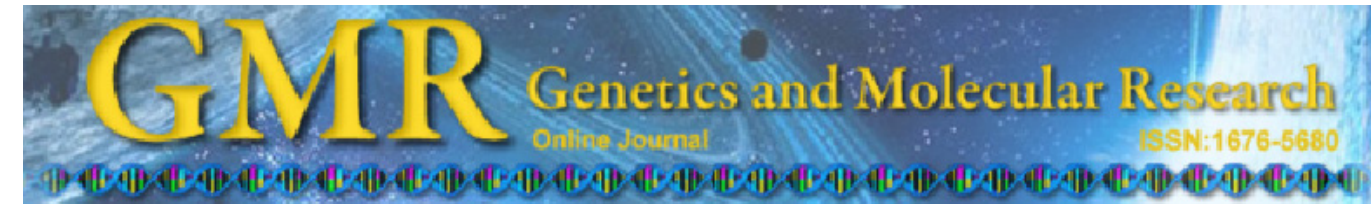

\title{
Candidate gene region for control of rib eye area in Canchim beef cattle
}

\author{
S.L. Meirelles ${ }^{1}$, G.V. Gouveia ${ }^{1}$, G. Gasparin ${ }^{2}$, M.M. Alencar ${ }^{3}$, \\ J.J.S. Gouveia ${ }^{4}$ and L.C.A. Regitano ${ }^{3}$ \\ ${ }^{1}$ Departamento de Genética e Evolução, \\ Universidade Federal de São Carlos, São Carlos, SP, Brasil \\ ${ }^{2}$ Escola Superior de Agricultura "Luiz de Queiroz", Universidade de São Paulo, \\ Piracicaba, SP, Brasil \\ ${ }^{3}$ Embrapa Pecuária Sudeste, São Carlos, SP, Brasil \\ ${ }^{4}$ Universidade Federal do Vale do São Francisco, Petrolina, PE, Brasil
}

Corresponding author: L.C.A. Regitano

E-mail: luciana@cppse.embrapa.br

Genet. Mol. Res. 10 (2): 1220-1226 (2011)

Received November 26, 2010

Accepted March 3, 2011

Published June 21, 2011

DOI 10.4238/vol10-2gmr1175

\begin{abstract}
Investigation of molecular marker effects on production traits is essential to define marker assisted selection strategies in beef cattle. We looked for a possible association of molecular markers and backfat thickness (BFT) and rib eye area (REA) in Canchim (5/8 Charolais $+3 / 8 \mathrm{Zebu}$ ) and MA (offspring of Charolais bulls and $1 / 2$ Canchim $+1 / 2$ Zebu cows) animals raised exclusively on pasture. Traits were measured on 987 individuals from seven herds from two Brazilian States (São Paulo and Goiás), in March and April from 2005 to 2007, when animals were, on average, 19 months of age. Five microsatellite markers lying in QTL regions for BFT and REA (BMS490 and ETH10 on chromosome 5, INRA133 and ILSTS090 on chromosome 6 , and BMS2142 on chromosome 19) were genotyped and association analyses were performed under an animal model using the restricted
\end{abstract}


maximum likelihood method. After correction for multiple tests, a significant effect of microsatellite BMS490 on REA was observed, suggesting that at least one QTL affecting carcass traits in this region of the BTA5. No significant effect on BFT was observed for these markers.

Key words: Association study; Carcass traits; Cattle; Microsatellite markers

\section{INTRODUCTION}

Carcass traits like backfat thickness (BFT) and rib eye area (REA) are important to determine production efficiency and beef yield. To be able to consider them as selection criteria in genetic evaluation and marker assisted selection programs, it is necessary to quantify their additive genetic variation and to evaluate the availability of genetic markers associated with them. Since marker-phenotype associations are population parameters and are susceptible to environmental influence, they require estimates for the population under selection as well as for the environmental conditions where traits are to be selected.

The ultrasound technique is an alternative for in vivo prediction of carcass traits. The measurement of REA and BFT could help to choose animals for slaughter and also provide important information for breeding programs (Arnold et al., 1991; Hamlin et al., 1995).

Brazilian beef cattle breeding programs are based on expected progeny differences derived from the phenotypes of animals. Although the majority of production traits are controlled by many genes, each one with a small effect, some of these genes may have greater importance in controlling certain phenotypes. Nowadays, it is possible to map genes or sets of genes that influence quantitative trait loci (QTL), enabling the use of molecular information in breeding programs, mainly for traits that are difficult or expensive to score, such as carcass, meat quality and disease resistance traits, as well as low heritability traits, such as reproductive traits (Dekkers, 2004; Nakvi, 2007).

The Canchim breed has good growth potential and tropical adaptation but suboptimal fat deposition. Currently, there are two genetic groups in the Canchim breed: MA (offspring of Charolais bulls and 1/2 Canchim $+1 / 2$ Zebu cows) and CA (offspring of MA x MA, MA x Canchim or Canchim x Canchim).

Previous studies found QTL for BFT and REA in several bovine chromosomes (Taylor et al., 1998; Casas et al., 2000, 2003; Kneeland et al., 2004), among them the chromosomes 5, 6 and 19. Therefore, the aim of this study was to investigate the association of molecular markers located on QTL regions of the bovine chromosomes 5, 6 and 19 on REA and BFT in a sample of Canchim beef cattle breed raised on pasture.

\section{MATERIAL AND METHODS}

\section{Animals and phenotypes}

Data from 987 half-sib offspring of 123 sires, both males and females, were used in this study. From these, 712 were Canchim (5/8 Charolais $+3 / 8$ Zebu) and 275 were MA. Ani- 
mals were born from 2003 to 2005 and raised exclusively on pasture in herds in the States of São Paulo and Goiás (Southeast and Central Brazil, respectively). Animals born in 2003 and 2004 were from two herds, while the rest were born in seven herds. Neither Canchim nor MA was subjected to considerable selection for carcass traits.

Backfat thickness and rib eye area measures were taken using ultrasound equipment in the longissimus area in the region between the 12th and the 13th rib. Measurements were performed in March and April from 2005 to 2007, when animals were between 16 and 22 months of age.

\section{DNA extraction and microsatellite markers}

From each animal, $5 \mathrm{~mL}$ blood was collected using vacuum tubes containing $50 \mu \mathrm{L}$ EDTA. Semen straws from the sires were donated by the breeders for subsequent conference of paternity. DNA was extracted from blood and semen samples using a salting out protocol. After the extraction, DNA was quantified in a spectrophotometer, diluted to $40 \mathrm{ng} / \mu \mathrm{L}$ and maintained at $-30^{\circ} \mathrm{C}$.

All animals (both sire and offspring) were genotyped using five microsatellite markers tagging three QTLs described in the literature on three chromosomes: BMS490 and ETH10 on chromosome $5(65.4$ and $70.0 \mathrm{cM})$; INRA133 and ILSTS090 on chromosome 6 (8.2 and 11.8 $\mathrm{cM})$, and BMS2142 on chromosome $19(44.7 \mathrm{cM})$. These positions were based on the NCBI DATABASE (www.ncbi.nlm.nih.gov) and primer sequences used in this study were obtained from the Meat Animal Research Center (MARC) database (http://www.marc.usda.gov).

Polymerase chain reaction (PCR) conditions were: $40 \mathrm{ng}$ genomic DNA; $50 \mathrm{mM}$ $\mathrm{KCl} ; 1.5 \mathrm{mM} \mathrm{MgCl} ; 10 \mathrm{mM}$ Tris-HCl, $\mathrm{pH} 8.4 ; 0.2 \mathrm{mM}$ each dNTP; $0.25 \mathrm{U}$ Taq DNA polymerase and $0.5 \mu \mathrm{M}$ of each primer. Amplification protocols consisted of an initial denaturation step of $3 \mathrm{~min}$ at $95^{\circ} \mathrm{C}$, followed by 28 cycles $\left(30 \mathrm{~s}\right.$ denaturation at $94^{\circ} \mathrm{C}, 30 \mathrm{~s}$ annealing at $58^{\circ} \mathrm{C}$ and $30 \mathrm{~s}$ extension at $72^{\circ} \mathrm{C}$ ) and then a final extension step of $45 \mathrm{~min}$ at $72^{\circ} \mathrm{C}$. Samples were analyzed in an automatic DNA sequencer ABI 3100 Avant (Applied Biosystems) and genotypes scored with GeneScan (version 3.7.1) and Genotyper (version 3.7) (Applied Biosystems). A sample of known genotype was placed on each plate analyzed for allele calling standardization.

\section{Statistical analysis}

In order to verify the genetic and environmental effects influencing carcass traits considered in the present study, analyses of variance were performed using the least squares means method. Variables included in the contemporary groups (CG) were: year of birth, herd, genetic group (Canchim or MA) and sex. CGs with less than two individuals were excluded from subsequent analyses and 32 CGs were created.

To verify the influence of the molecular markers on carcass traits, an animal model considering CG and marker genotypes as fixed effects, age of the animal (covariate, linear), as well as direct and residual random effects, was used. Analyses were performed with the restricted maximum likelihood method (REML) using the ASREML software (Gilmour et al., 2000) following Schenkel et al. (2005), who used the same software to test the association between SNPs in the leptin gene and carcass traits. The inverse of the genetic relationship matrix 
contained 3946 different animals.

All analyses were performed individually for each of the five markers, considering simultaneously a pair of markers located in the same chromosome (BMS490 and ETH10 on BTA5 and INRA133 and ILSTS090 on BTA6). Alleles and genotypes that presented frequency lower than $1 \%$ were excluded from all analyses. This procedure was adopted since frequencies lower than $1 \%$ could result from genotyping error. As a consequence of this data discard, some allele frequencies that were higher in the initial data set fell below a frequency of $1 \%$ after the discard.

The statistical model used for both traits was

$$
y=X \beta+Z a+e
$$

(Equation 1)

in which: $y$ is the vector of observation; $X$ is the incidence matrix of fixed effects; $\beta$ is the vector of fixed effects (contemporary group, age and genotypes); $Z$ is the incidence matrix that relates the registries to the random additive genetic effect; $a$ is the vector of the unknown random additive genetic effect, and $e$ is the vector of error. When a significant marker effect $(\mathrm{P} \leq$ 0.05 ) was found for REA, the same model was applied to verify association with body weight. The significance threshold was corrected by the sequential Bonferroni's correction using the method described by Holm (1979).

When the marker effect was significant $(\mathrm{P} \leq 0.05)$ in the REML analysis, the allelic substitution effect was calculated as a deviation from the most frequent allele for the marker locus using a regression analysis where the genotype effect (class effect) was substituted by covariates representing the number of each allele on the genotype. To test for the presence of deviations from the additive model, a likehood ratio test (Mood et al., 1974) was applied to compare the model including the marker genotype with the model including only the allelic substitution effects.

\section{RESULTS AND DISCUSSION}

Means for REA $(46.6 \pm 9.19)$ and BFT $(1.90 \pm 0.77)$ were similar to those observed by Yokoo et al. (2010) in Nellore animals measured at the same age. Several authors, studying Hereford, Brangus, Angus, and Santa Gertrudis breeds, found higher values for REA and lower values for BFT (Turner et al., 1990; Arnold et al., 1991; Moser et al., 1998; Kemp et al., 2002) in animals with 320-369 days of age that were supplemented and mostly male. Values observed in these studies were between 47.46 and $86.0 \mathrm{~cm}^{2}$ for REA and from 0.47 to $0.95 \mathrm{~mm}$ for BFT. The lower values of backfat thickness in those articles may have been found because these traits were measured at earlier ages and mainly in males, which deposit subcutaneous fat later than females.

The markers BMS490, ETH10, ILSTS090, INRA133, and BMS2142 presented 13, 9 , 5,15 , and 16 alleles, respectively, in the Canchim population.

In the single marker analysis, the BMS490 locus showed significant effect on REA (P $<0.05$ ) (Table 1). This result is in accordance with Casas et al. (2003) who mapped a QTL for the same trait on the corresponding chromosomal region (53 to $75 \mathrm{cM}$ on BTA5) in Bos indicus $\mathrm{x}$ Bos taurus cattle. Close to this microsatellite marker (BMS490) is located the growth differentiation factor 6 gene (GDF6) $(66.2 \mathrm{cM})$. 
Table 1. Level of significance of sources of variation considered in the analyses of variance of rib eye area (REA) and backfat thickness (BFT).

\begin{tabular}{lccc}
\hline Source of variation & Degrees of freedom & REA P value & BFT P value \\
\hline Contemporary group & 31 & $<0.001$ & $<0.001$ \\
Age (linear) & 1 & $<0.001$ & $<0.001$ \\
BMS4901 & 17 & 0.012 & 0.626 \\
ETH10 & 9 & 0.724 & 0.321 \\
BMS2142 & 20 & 0.540 & 0.172 \\
ILSTS090 & 4 & 0.298 & 0.815 \\
INRA133 $^{1}$ & 12 & 0.408 & 0.469 \\
\hline
\end{tabular}

${ }^{1}$ Considering each genotype separately in each analysis. Genotypes with less than $1 \%$ were excluded from the analysis.

One of the functions of this gene is to stimulate cellular growth or differentiation (http://www.ebi.ac.uk/QuickGO/GProtein?ac=P55106). This gene may be a good candidate for harboring the true causal mutation underlying the REA variation associated with the marker BMS490. Association between a molecular marker and rib eye area is of great interest for the beef cattle industry because this trait is related to the amount of muscle in the carcass (Boggs and Meyer, 1990).

To confirm that the effect of BMS490 was not a result of linkage disequilibrium with the other marker on BTA5, because they are located $4.6 \mathrm{cM}$ apart on the same chromosome, this marker was included in the model together with ETH10. The effect of BMS490 on REA remained $(\mathrm{P}<0.01)$, suggesting that the effect observed did not result from the combination of the two markers. After sequential Bonferroni's correction all results were confirmed at the same level of significance.

Given that BMS490 marker showed significant effect on REA, the average allele substitution effects were estimated (Table 2). The substitution of the more frequent allele 178 by the 176, 182 and 190 alleles indicated significant average effects $(\mathrm{P}<0.05)$, suggesting that these substitutions contribute to the variation in the mean rib eye area of the population. Alleles 182 and 190 would increase, on average, the REA of the homozygote (178178) by 1.29 and $4.95 \mathrm{~cm}^{2}$, respectively. The 176 allele would decrease, on average, the REA by $2.20 \mathrm{~cm}^{2}$ in the Canchim populations studied.

Table 2. Allele substitution effect for BMS490 on rib eye area, regression coefficient and allele frequencies.

\begin{tabular}{lcccc}
\hline Source of variation & Degrees of freedom & $\mathrm{P}$ & Regression coefficient $\left(\mathrm{cm}^{2}\right)$ & Allele frequencies $(\%)$ \\
\hline Mean & 1 & $<0.001$ & - & - \\
CG & 31 & $<0.001$ & $-0.7222 \pm 1.945$ & 0.71 \\
Allele $170^{1}$ & 1 & 0.712 & $-2.208 \pm 0.969$ & 2.96 \\
Allele $176^{1}$ & 1 & 0.024 & $0.100 \pm 1.041$ & 10.54 \\
Allele $180^{1}$ & 1 & 0.923 & $1.286 \pm 0.580$ & 10.18 \\
Allele $182^{1}$ & 1 & 0.028 & $-0.666 \pm 0.609$ & 36.09 \\
Allele $184^{1}$ & 1 & 0.275 & $0.363 \pm 0.363$ & 0.59 \\
Allele $186^{1}$ & 1 & 0.321 & $4.950 \pm 2.111$ & - \\
Allele $190^{1}$ & 1 & 0.020 & - & \\
Age & 1 & $<0.001$ & & \\
\hline
\end{tabular}

${ }^{1}$ The allele substitution effects were calculated as deviations from the more frequent allele 178. 
The observed frequency (Table 2) of the allele with larger average favorable effect on REA (190) indicates that marker assisted selection based on this locus is feasible.

The model considering the BMS490 genotype's fixed effect was significantly different $(\mathrm{P}<0.05)$ from the model including the covariates for each marker allele, according to the maximum likelihood model comparison test. This result implies that, besides the additive effects of allelic substitution, there are important non-additive effects influencing this markertrait association.

Since variation in REA could be related to the animal's body size instead of muscling itself, a further analysis was performed under the same model used for marker association to REA, but considering the effect of BMS490 on body weight at the same age as REA was measured. No significant effect of BMS490 on weight was observed, suggesting that the observed association with REA is independent of body weight and is presumably related to muscling.

No effect was observed for BMS490 on BFT. To the other four markers, no effects on the two traits considered were found (Table 1). Results presented here do not confirm previous reports that suggest the presence of QTL influencing BFT in the regions studied, although it does not mean that there is no association of this chromosome region with BFT and REA since a limited number of markers were used. Taylor et al. (1998), working with Brangus and Angus cattle, found QTL for BFT and a percentage of ether extractable fat on chromosomal regions located at approximately $60-80 \mathrm{cM}$ on chromosome 19. Casas et al. (2000), working with Belgian Blue x MARC III and Piedmontese x Angus, found a QTL for BFT in the region between 40 and $80 \mathrm{cM}$ on chromosome 5 , and the existence of sets of genes responsible for variation in BFT with detectable effects was described by Kneeland et al. (2004) for Angus.

Yokoo et al. (2009), while studying Nellore animals, found genetic correlation between REA and visual score for muscle (0.61), indicating that, in the long term, the use of REA as a selection criterion might produce animals with higher visual scores for muscle.

\section{CONCLUSION}

There is at least one QTL for muscularity on BTA5 close to the marker BMS490, which is segregating in the studied synthetic population. More studies are needed to identify the gene (or genes) involved in the control of the trait.

\section{ACKNOWLEDGMENTS}

The authors thank Água Marinha, Calabilu, Embrapa Pecuária Sudeste, Paraíso, Santana, Santa Helena, and Vista Bonita for support with phenotypic data and DNA collection, and Dr. Flávio Shenckel (University of Guelph) for helpful advice on the data analyses. Research supported by Embrapa and CAPES (scholarships awarded to S.L. Meirelles).

\section{REFERENCES}

Arnold JW, Bertrand JK, Benyshek LL and Ludwig C (1991). Estimates of genetic parameters for live animal ultrasound, actual carcass data, and growth traits in beef cattle. J. Anim. Sci. 69: 985-992.

Boggs DL and Meyer AR (1990). Live Animal Carcass Evaluation in Selection Manual. 3rd edn. Kendall/Hunt Publishing Co. Press, Dubuque, 211.

Casas E, Shackelford SD, Keele JW, Stone RT, et al. (2000). Quantitative trait loci affecting growth and carcass 
composition of cattle segregating alternate forms of myostatin. J. Anim. Sci. 78: 560-569.

Casas E, Shackelford SD, Keele JW, Koohmaraie M, et al. (2003). Detection of quantitative trait loci for growth and carcass composition in cattle. J. Anim. Sci. 81: 2976-2983.

Dekkers JC (2004). Commercial application of marker- and gene-assisted selection in livestock: strategies and lessons. $J$. Anim. Sci. 82 (E-Suppl): E313-E328.

Gilmour AR, Cullis BR, Welham SJ and Thompson DR (2000). ASREML Reference Manual. IACR-Rothamsted Experimental Station, Harpenden.

Hamlin KE, Green RD, Cundiff LV, Wheeler TL, et al. (1995). Real-time ultrasonic measurement of fat thickness and longissimus muscle area: II. Relationship between real-time ultrasound measures and carcass retail yield. J. Anim. Sci. 73: 1725-1734.

Holm S (1979). A simple sequencial rejective multiple test procedure. Scand. J. Stat. 6: 65-70.

Kemp DJ, Herring WO and Kaiser CJ (2002). Genetic and environmental parameters for steer ultrasound and carcass traits. J. Anim. Sci. 80: 1489-1496.

Kneeland J, Li C, Basarab J, Snelling WM, et al. (2004). Identification and fine mapping of quantitative trait loci for growth traits on bovine chromosomes 2, 6, 14, 19, 21, and 23 within one commercial line of Bos taurus. J. Anim. Sci. 82: 3405-3414.

Mood AM, Graybill FA and Boes DC (1974). Tests of Hypotheses. In: Introduction to the Theory of Statistics. 3rd edn. (Mood AM, Graybill FA and Boes DC, eds.). McGraw-Hill Press, Tokyo, 401-470.

Moser DW, Bertrand JK, Misztal I, Kriese LA, et al. (1998). Genetic parameter estimates for carcass and yearling ultrasound measurements in Brangus cattle. J. Anim. Sci. 76: 2542-2548.

Nakvi AN (2007). Application of molecular genetic technologies in livestock production: potentials for developing countries. Advan. Biol. Res. 1: 72-84.

Schenkel FS, Miller SP, Ye X, Moore SS, et al. (2005). Association of single nucleotide polymorphisms in the leptin gene with carcass and meat quality traits of beef cattle. J. Anim. Sci. 83: 2009-2020.

Taylor JF, Coutinho LL, Herring KL, Gallagher DS Jr, et al. (1998). Candidate gene analysis of GH1 for effects on growth and carcass composition of cattle. Anim. Genet. 29: 194-201.

Turner JW, Pelton LS and Cross HR (1990). Using live animal ultrasound measures of ribeye area and fat thickness in yearling Hereford bulls. J. Anim. Sci. 68: 3502-3506.

Yokoo MJI, Werneck JN, Pereira MC, Albuquerque LG, et al. (2009). Correlações genéticas entre escores visuais e características de carcaça medidas por ultrassom em bovinos de corte. Pesq. Agropec. Bras. 44: 197-202.

Yokoo MJ, Lobo RB, Araujo FR, Bezerra LA, et al. (2010). Genetic associations between carcass traits measured by realtime ultrasound and scrotal circumference and growth traits in Nelore cattle. J. Anim. Sci. 88: 52-58. 